\title{
Final results from IMPROVE: a randomized, controlled, open-label, two-arm, cross-over phase IV study to determine patients' preference for everolimus in combination with exemestane or capecitabine in combination with bevacizumab in advanced HR-positive, HER2-negative breast cancer
}

Thomas Decker ${ }^{1}$, Ulrike Söling ${ }^{2}$, Antje Hahn ${ }^{3}$, Christoph Maintz ${ }^{4}$, Christian Martin Kurbacher ${ }^{5}$, Ursula Vehling-Kaiser ${ }^{6}$, Dagmar Sent ${ }^{7}$, Peter Klare ${ }^{8}$, Volker Hagen $^{9}$, Marco Chiabudini ${ }^{10}$, Julia Falkenstein ${ }^{10}$, Martin Indorf ${ }^{10}$, Eva Runkel ${ }^{10}$ and Karin Potthoff ${ }^{10^{*}}$

\footnotetext{
Abstract

Background: The objective of the IMPROVE study was patients' preference for either endocrine-based therapy or combined chemo- and anti-angiogenic therapy in advanced HR-positive/HER2-negative breast cancer.

Methods: In this randomized, cross-over phase IV study, 77 patients were recruited in 26 sites in Germany. Patients were randomized 1:1 to receive either capecitabine plus bevacizumab (Cap+Bev) as first-line therapy followed by cross-over to everolimus plus exemestane (Eve+Exe) as second-line therapy (Arm A) or the reverse sequence (Arm B). The primary endpoint was patients' preference for either regimen, assessed by the Patient Preference Questionnaire 12 weeks after cross-over. Key secondary endpoints included progression-free survival (PFS), overall survival (OS), safety, and quality of life (QoL).

\footnotetext{
* Correspondence: manuscript@iomedico.com

${ }^{10}$ iOMEDICO AG, Ellen-Gottlieb-Straße 19, 79106 Freiburg im Breisgau, Germany

Full list of author information is available at the end of the article
}

C C The Author(s). 2020 Open Access This article is licensed under a Creative Commons Attribution 4.0 International License, which permits use, sharing, adaptation, distribution and reproduction in any medium or format, as long as you give appropriate credit to the original author(s) and the source, provide a link to the Creative Commons licence, and indicate if changes were made. The images or other third party material in this article are included in the article's Creative Commons licence, unless indicated otherwise in a credit line to the material. If material is not included in the article's Creative Commons licence and your intended use is not permitted by statutory regulation or exceeds the permitted use, you will need to obtain permission directly from the copyright holder. To view a copy of this licence, visit http:/creativecommons.org/licenses/by/4.0/. The Creative Commons Public Domain Dedication waiver (http://creativecommons.org/publicdomain/zero/1.0/) applies to the data made available in this article, unless otherwise stated in a credit line to the data. 
(Continued from previous page)

Results: $61.5 \%$ of patients preferred Cap+Bev ( $p=0.1653)$, whereas $15.4 \%$ preferred Eve+Exe and $23.1 \%$ were indecisive. Physicians showed a similar tendency towards Cap+Bev (58.1\%) as the preferred regimen versus Eve+Exe (32.3\%). Median first-line PFS was longer for Cap+Bev than for Eve+Exe (11.1 months versus 3.5 months). Median second-line PFS was similar between Cap+Bev and Eve+Exe (3.6 months versus 3.7 months). Median OS was comparable between Arm A (28.8 months) and Arm B (24.7 months). 73.0\% and 52.6\% (first-/second-line, Cap+Bev) and $54.1 \%$ and $52.9 \%$ (first-/second-line, Eve+Exe) of patients experienced grade 3/4 TEAEs. No treatment-related deaths occurred. QoL and treatment satisfaction were not significantly different between arms or treatment lines.

Conclusions: Patients tended to favor Cap+Bev over Eve+Exe, which was in line with physicians' preference. Cap+Bev showed superior first-line PFS, while QoL was similar in both arms. No new safety signals were reported.

Trial registration: EudraCT No: 2013-005329-22. Registered on 19 August 20

Keywords: Advanced breast Cancer, Endocrine therapy, Combined chemo- and anti-Angiogenic therapy, Patient preference, Randomized, cross-over phase IV study

\section{Background}

Breast cancer $(\mathrm{BC})$ is the second-most common cancer worldwide. Approximately $20-30 \%$ of all patients treated with curative intent develop metastatic BC (MBC) [1]. Depending on subtype, systemic treatment of advanced $\mathrm{BC}$ (locally recurrent and inoperable or $\mathrm{MBC}$ ) offers a wide range of options including endocrine therapy, immunochemotherapy, kinase inhibitors, radiation therapy, and supportive measures. For postmenopausal patients with advanced hormone receptor-positive/human epidermal growth factor receptor 2-negative (HR-positive/HER2negative) $\mathrm{BC}$ various treatment options exist. Current international guidelines recommend endocrine therapy as the first-line treatment of choice in the vast majority of these patients. Chemotherapy may be considered as a reasonable alternative in patients for whom endocrine treatment is inappropriate including individuals presenting with acute visceral crisis and/or hormone-resistant tumors [2-4]. Up to now, there are limited data from clinical trials having directly compared chemotherapy and endocrinebased treatment in patients with $\mathrm{MBC}$. A previous metaanalysis reported similar efficacy of both treatment strategies, however, the drugs utilized were outdated as per today's standard of care [5].

Capecitabine (Cap) + bevacizumab (Avastin ${ }^{\bullet}$ Bev) combination therapy is indicated for first-line treatment of adult patients with $\mathrm{MBC}$ for whom treatment with taxanes and/or anthracyclines is inappropriate [6-9]. Regarding endocrine therapy, the everolimus (Afinitor ${ }^{\oplus}$, Eve) + exemestane (Aromasin ${ }^{\odot}$, Exe) combination is indicated in postmenopausal patients with advanced HRpositive, HER2-negative BC after recurrence or progression following treatment with non-steroidal aromatase inhibitors [10-13].

Assuming comparable efficacy between different therapeutic options, it is of utmost importance to identify the treatment with the least negative impact on patients' quality of life (QoL). The IMPROVE study evaluated patients' preference for either combined antihormonal therapy (everolimus + exemestane, Eve+Exe) or combined chemo- and anti-angiogenic therapy (capecitabine + bevacizumab, Cap+Bev) in postmenopausal patients with advanced HR-positive, HER2-negative BC and indication for first-line chemotherapy or endocrine therapy after failure of $\geq 1$ standard non-steroidal aromatase inhibitor therapy.

\section{Methods}

\section{Patients}

Eligible patients were aged $\geq 18$ years, postmenopausal, diagnosed with HR-positive, HER2-negative advanced $\mathrm{BC}$ (locally recurrent and inoperable or $\mathrm{MBC}$ ), with indication for first-line chemotherapy or endocrine therapy after failure of $\geq 1$ non-steroidal aromatase inhibitor therapy, no indication for treatment with taxanes and/or anthracyclines, measurable or non-measurable disease according to RECIST v1.1 [14], adequate bone marrow and organ function as per current Summary of Product Characteristics $(\mathrm{SmPC})$ of respective study drug $[8,9$, $12,13]$, ECOG performance status $\leq 2$, and fluency in German. Key exclusion criteria included prior palliative cytotoxic chemotherapy, prior treatment with mTOR (mammalian target of rapamycin)-inhibitors (prior treatment with exemestane was permitted), symptomatic visceral metastases, unstable skeletal metastases, medically uncontrolled cardiovascular diseases or diabetes mellitus, and known dihydropyrimidine dehydrogenase deficiency.

\section{Study design and endpoints}

This open-label, randomized, controlled, multicenter, two-arm, cross-over phase IV study (EudraCT No 2013005329-22) randomly assigned patients (1:1) to receive either $\mathrm{Cap}+\mathrm{Bev}$ first-line therapy during the first treatment phase (TP) followed by cross-over to Eve+Exe as secondline therapy during the second TP (Arm A) or the reverse 
sequence (Arm B; Fig. 1). For allocation of patients, a computer-generated randomization list was used to automatically allocate patients in the electronic Case Report Form by using an integrated randomization tool within the Electronic Data Capture system. Patients were stratified by (i) visceral metastases versus non-visceral metastases, (ii) prior (neo) adjuvant treatment (anthracycline and/ or taxane; yes versus no), (iii) number of prior palliative anti-hormonal therapies ( $0-1$ versus $>1$ ) and (iv) diseasefree interval (DFI; $\leq 2$ years versus $>2$ years) by using a permuted block randomization with block lengths of two and four. DFI was defined as the time from first R0 resection until first local relapse or occurrence of distant metastases, whichever occurred first. The block sizes were not disclosed to ensure concealment. Patients were treated in each TP until progression, intolerable toxicity, or withdrawal of consent. Each TP was separated by a washout phase (7-28 days). Dosing and administration of the study drugs are detailed in Table 1.

The primary endpoint was patients' preference for either $\mathrm{Cap}+\mathrm{Bev}$ or Eve+Exe combination therapy, assessed by questionnaire 12 weeks after cross over. Key secondary endpoints included progression-free survival (PFS), overall survival (OS), treatment satisfaction, QoL, and safety.

\section{Questionnaires}

Patients' treatment preference was assessed by the $\mathrm{Pa}$ tient Preference Questionnaire (PPQ) 12 weeks after cross over. Patients having discontinued therapy after $<$ 12 weeks of treatment were asked to complete the PPQ
Table 1 Dose and mode of administration of the study drugs ${ }^{a}$

\begin{tabular}{ll}
\hline Study drug & Dose and mode of administration \\
\hline Capecitabine & $\begin{array}{l}1000 \mathrm{mg} / \mathrm{m}^{2} \text { per os twice daily as combined } 150 \mathrm{mg} \text { and } \\
500 \mathrm{mg} \text { tablets on days } 1 \text { to } 14 \text { of each } 21 \text {-day cycle, } \\
\text { followed by a } 7 \text {-day resting period (i.e. off-treatment) }\end{array}$ \\
Bevacizumab $\begin{array}{ll}15 \mathrm{mg} / \mathrm{kg} \text { intravenously once every } 3 \text { weeks (i.e. } 5 \mathrm{mg} / \mathrm{kg} / \\
\text { week dose equivalent) }\end{array}$ \\
$\begin{aligned} 10 \mathrm{mg} \text { per os once daily of each } 21 \text {-day cycle } \\
\text { Exerolimus }\end{aligned}$
\end{tabular}

${ }^{a}$ Dose and mode of administration of the study drugs were in accordance with current SmPC of respective study drug. Study drugs were available upon prescription by respective treating physician. A cycle was defined as 21 days of study treatment

within 2 weeks of treatment discontinuation. Patients were asked in the PPQ for their treatment preference $(\mathrm{Cap}+\mathrm{Bev}, \mathrm{Eve}+\mathrm{Exe}$, or no preference) and reason for their preference. Similarly, physicians were asked for their treatment preference (case-based), assessed by the Physician Preference Questionnaire. Patients were asked to complete the Treatment Satisfaction Questionnaire in week 12 of each TP. Additionally, patients were asked to complete QoL questionnaires in each TP (baseline and at week 12) including the European Organisation for Research and Treatment of Cancer (EORTC) quality of life questionnaire (QLQ)-C30 questionnaire [15].

\section{Tumor assessment and adverse events}

Tumor evaluation according to RECIST v1.1 was to be performed by the investigator at screening, every 12 weeks and at end of each TP, and every 6 months during

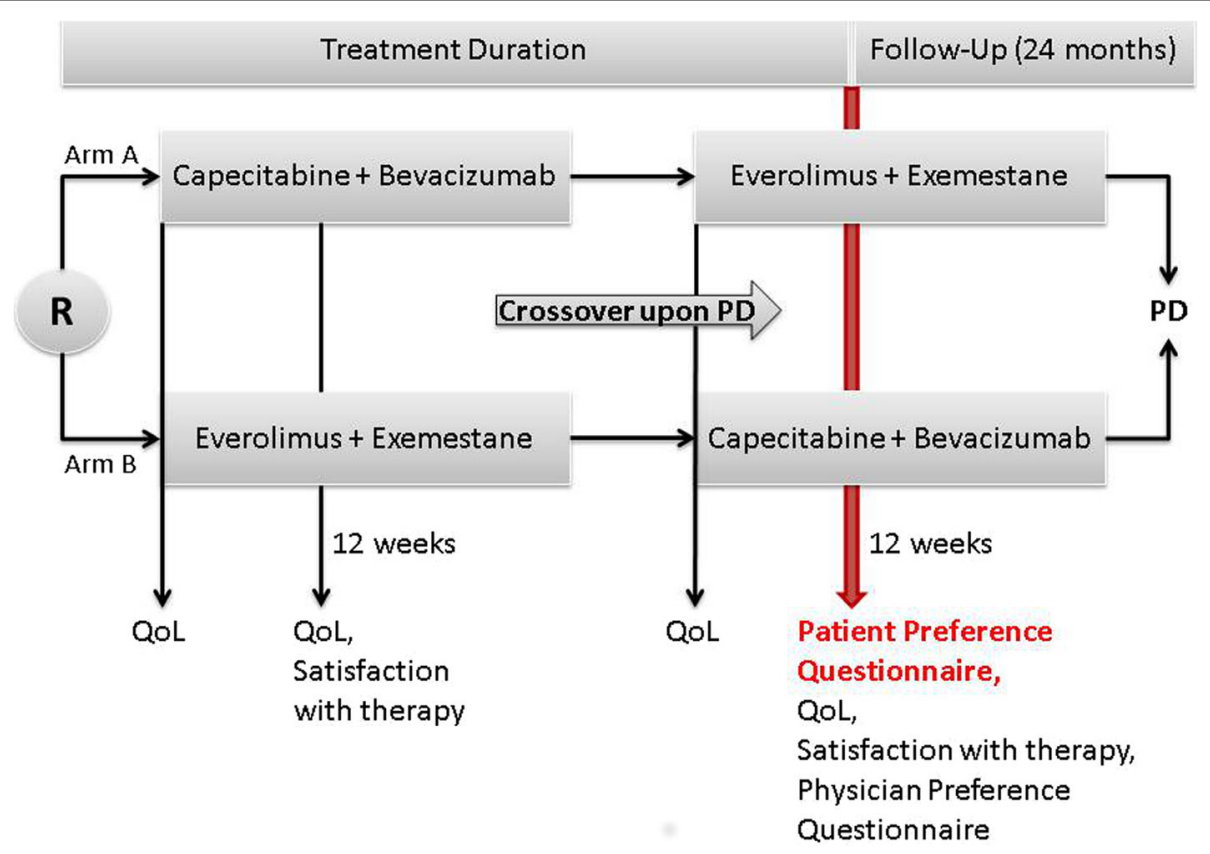

Fig. 1 Overall Study Design. Duration of follow-up: $\geq 24$ months, until death or end of study. $R=$ randomization; PD = progressive disease; $Q 0 L=$ quality of life 
follow-up (FU; $\geq 24$ months or until death). During the FU, patients were also assessed for survival status. Any treatment-emergent adverse event (TEAE) and toxicity were to be recorded from day of first administration of study treatment until 30 days after end of treatment in each TP. TEAEs were graded by the investigator according to NCI CTCAE v4.03 [16].

\section{Statistical analysis}

The initial null hypothesis stated that there is no difference in patients' preference for either regimen assuming that $80 \%$ of patients do have a preference, whereas $20 \%$ cannot decide. The study was designed to control the $\alpha$ error rate at 0.05 with a power of $80 \%$. Required sample size was estimated to 192 patients assuming a drop-out rate at 35\%. The assumptions for the null hypotheses were chosen according to the PISCES trial [17].

The intent-to-treat (ITT) population comprised all patients to whom study treatment had been assigned by randomization. The modified ITT (mITT) population was used to assess the primary endpoint and was predefined as all patients who had received both firstline and second-line therapy for $\geq 12$ weeks per line or less for other reasons than progressive disease (PD), crossed over to second-line therapy within 12 weeks of termination of first-line therapy, and answered the preference question. Additionally, the primary endpoint was assessed in a post hoc analysis by using the per-protocol (PP) population including all patients who had received $\geq 1$ dose of study medication in first-line and second-line therapy and answered the preference question. The safety set (SAF) included all patients who had received $\geq 1$ dose of study medication.

To analyze the primary endpoint and to test the significance of difference in patient preference between the regimens, a Chi-square test was used to compare the actual preference against the null hypothesis of no difference in patient preference taking into account the proportion of indifferent patients. For the final analysis, the null hypothesis was adopted for the actually observed proportion of indifferent patients. By this means, the actual null hypothesis for

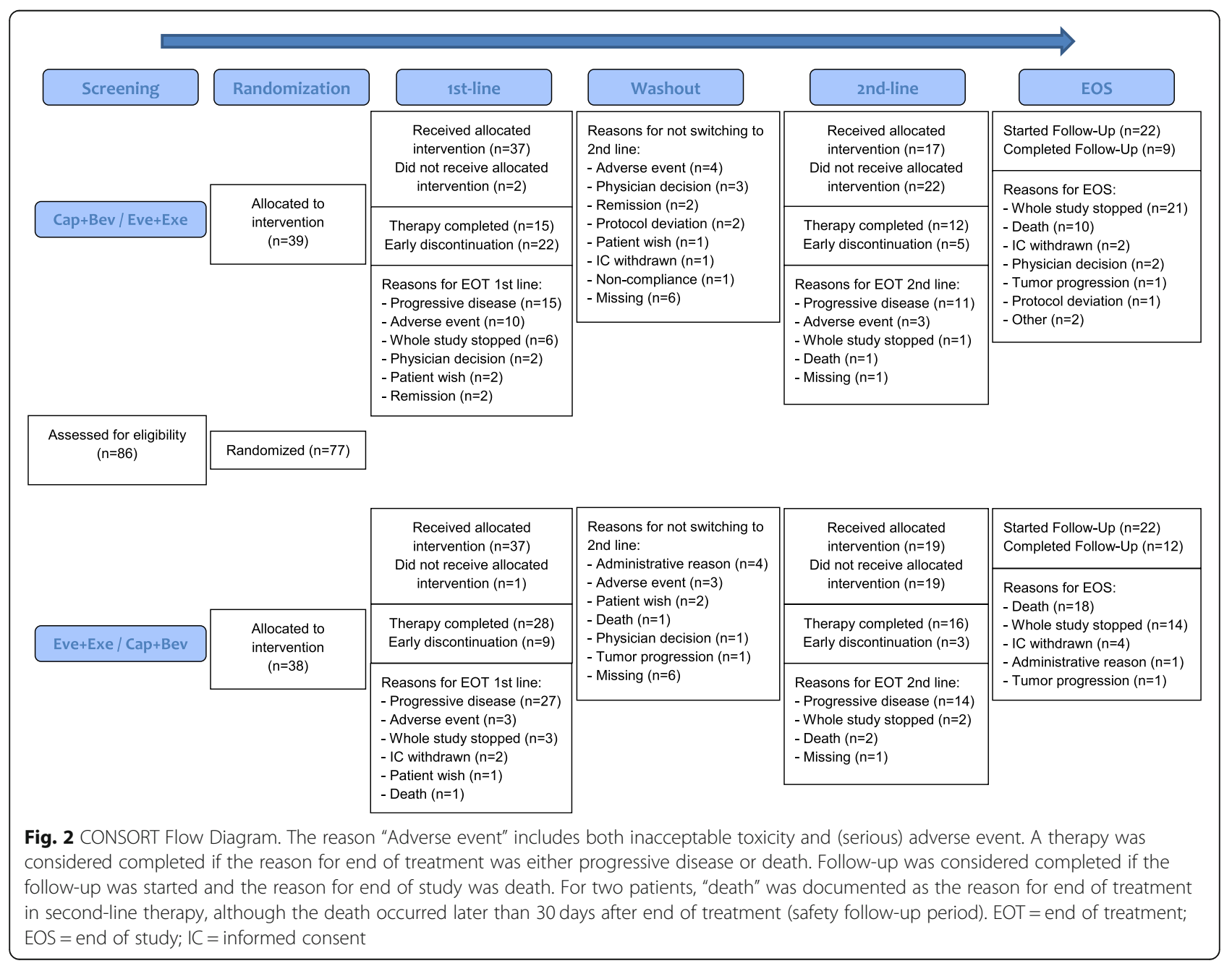


the primary analysis was $38.45 \%$ prefer $\mathrm{Cap}+\mathrm{Bev}$, $38.45 \%$ prefer Eve+Exe, and $23.1 \%$ are indifferent about their preference. Reasons for preference were analyzed descriptively.

Difference in overall treatment satisfaction was analyzed by using an asymptotic chi-square test (satisfied versus not satisfied).

The EORTC QLQ-C30 questionnaire was analyzed descriptively. Differences in scores were evaluated by a t-test.

PFS and OS were estimated by using the KaplanMeier method [18].

The primary endpoint was further evaluated by age $(<$ 60 years vs. $\geq 60$ years) in the mITT, ITT and PP populations. However, further subgroup and explorative analyses pre-planned for the primary endpoint were not performed due to low number of available observations (mITT; $N=13)$.

\section{Results}

This study was initially planned to enroll 192 patients. Due to emergence of new treatment options and low recruitment rate, the recruitment was stopped after 77 patients had been randomized. The study was prematurely terminated in September 2017.

\section{Disposition of patients}

Seventy-seven patients (ITT population) were recruited from October 2014 through April 2017 in 26 sites in Germany (Fig. 2); 39 patients were randomized to Arm A (Cap+Bev / Eve+Exe) and 38 patients to Arm B (Eve+Exe / Cap+Bev). In Arm A, 37 of the 39 randomized patients received the allocated firstline therapy. Of these, 17 patients crossed over to second-line therapy. In Arm B, 37 of the 38 randomized patients received the allocated first-line therapy. Of these, 19 patients crossed over to second-line therapy. Overall, 44 patients started the FU, which was planned to last $\geq 24$ months or until death (FU completed: $n=21$ ).

The mITT population comprised 13 patients (Arm A: $N=5$; Arm B: $N=8$ ) and the PP population 31 patients (Arm A: $N=13$; Arm B: $N=18$ ). The SAF population was used to analyze TEAEs in first-line (Arm A: $N=37$; Arm B: $N=37$ ) and second-line therapy (Arm A: $N=17$; Arm B: $N=19$ ).

\section{Patient characteristics at baseline}

All patients had HR-positive, HER2-negative BC. Baseline patient demographics, clinical characteristics, and treatment history in the randomized ITT population were balanced between study arms (Table 2).
Table 2 Patient characteristics at baseline (ITT population)

\begin{tabular}{|c|c|c|}
\hline & $\begin{array}{l}\text { Arm A (Cap+Bev / } \\
\text { Eve+Exe) }(N=39)\end{array}$ & $\begin{array}{l}\text { Arm B (Eve+Exe / } \\
\text { Cap+Bev) }(N=38)\end{array}$ \\
\hline Age [years], median (range) & $64.4(47.0-83.6)$ & $65.9(49.8-86.0)$ \\
\hline \multicolumn{3}{|l|}{ Ethnicity, n (\%) } \\
\hline Caucasian & $38(97.4 \%)$ & $37(97.4 \%)$ \\
\hline Asian & $1(2.6 \%)$ & $1(2.6 \%)$ \\
\hline $\begin{array}{l}\text { BMI }\left[\mathrm{kg} / \mathrm{m}^{2}\right] \text {, median } \\
\text { (quartiles) }\end{array}$ & $25.6(22.5-28.4)$ & $24.9(22.7-31.1)$ \\
\hline \multicolumn{3}{|l|}{ ECOG Performance Status, n (\%) } \\
\hline 0 & $19(48.7 \%)$ & $17(44.7 \%)$ \\
\hline 1 & $19(48.7 \%)$ & $20(52.6 \%)$ \\
\hline 2 & $1(2.6 \%)$ & $1(2.6 \%)$ \\
\hline \multicolumn{3}{|l|}{ Menopausal status, n (\%) } \\
\hline Postmenopausal & $39(100 \%)$ & $38(100 \%)$ \\
\hline \multicolumn{3}{|l|}{ Concomitant diseases, n (\%) } \\
\hline Yes & $33(84.6 \%)$ & $35(92.1 \%)$ \\
\hline No & $6(15.4 \%)$ & $3(7.9 \%)$ \\
\hline $\begin{array}{l}\text { Visceral disease or local } \\
\text { relapse, n (\%) }\end{array}$ & $27(69.2 \%)$ & $26(68.4 \%)$ \\
\hline Non-visceral disease, n (\%) & $12(30.8 \%)$ & $12(31.6 \%)$ \\
\hline \multicolumn{3}{|l|}{ Metastatic sites ${ }^{\mathrm{a}}, \mathrm{n}(\%)$} \\
\hline Bone & $28(71.8 \%)$ & $29(76.3 \%)$ \\
\hline Liver & $15(38.5 \%)$ & $16(42.1 \%)$ \\
\hline Lung & $8(20.5 \%)$ & $10(26.3 \%)$ \\
\hline \multicolumn{3}{|l|}{ Histology of tumor, n (\%) } \\
\hline Invasive ductal & $27(69.2 \%)$ & $24(63.2 \%)$ \\
\hline Invasive lobular & $7(17.9 \%)$ & $12(31.6 \%)$ \\
\hline Inflammatory cancer & $1(2.6 \%)$ & 0 \\
\hline Not otherwise specified & $4(10.3 \%)$ & $2(5.3 \%)$ \\
\hline $\mathrm{DFI}^{\mathrm{b}}$ [years], median (quartiles) & $4.7(1.4-10.9)$ & $5.0(1.3-8.2)$ \\
\hline $\begin{array}{l}\text { Time since initial diagnosis } \\
\text { [years], median (quartiles) }\end{array}$ & $9.6(3.6-13.0)$ & $6.6(2.5-10.0)$ \\
\hline $\begin{array}{l}\text { Time since first relapse }{ }^{c} \\
\text { [years], median (quartiles) }\end{array}$ & $8.4(0.6-23.4)$ & $5.1(1.5-15.1)$ \\
\hline $\begin{array}{l}\text { Any prior adjuvant } \\
\text { chemotherapy, n (\%) }\end{array}$ & $22(56.4 \%)$ & $28(73.7 \%)$ \\
\hline $\begin{array}{l}\text { Prior adjuvant taxane and/or } \\
\text { anthracycline therapy, } \mathrm{n}(\%)\end{array}$ & $22(56.4 \%)$ & $26(68.4 \%)$ \\
\hline \multicolumn{3}{|c|}{ Number of prior palliative endocrine therapies, n (\%) } \\
\hline 1 & $10(25.6 \%)$ & $13(34.2 \%)$ \\
\hline 2 & $11(28.2 \%)$ & $10(26.3 \%)$ \\
\hline 3 & $1(2.6 \%)$ & 0 \\
\hline
\end{tabular}

${ }^{a}$ Multiple answers per patient were possible. ${ }^{b} \mathrm{DFI}$ was defined as the time from first Ro resection until first local relapse or occurrence of distant metastases, whichever occurred first. 'Includes both local breast cancer recurrence and distant metastases. $\mathrm{BMI}=$ body mass index; $\mathrm{ECOG}=$ Eastern Cooperative Oncology Group; DFI = disease-free interval 
Table 3 Rates of patients' preference ${ }^{a}$ (mITT/ITT/PP population)

\begin{tabular}{|c|c|c|c|c|c|c|}
\hline \multirow[t]{2}{*}{$\mathrm{mlTT}$} & \multicolumn{2}{|c|}{$\operatorname{Arm} \mathrm{A}(\mathrm{N}=5)$} & \multicolumn{2}{|c|}{ Arm B $(N=8)$} & \multicolumn{2}{|c|}{ Total $(N=13)$} \\
\hline & $\overline{n(\%)}$ & $95 \%-\mathrm{Cl}$ & $\overline{n(\%)}$ & $95 \%-\mathrm{Cl}$ & $\overline{n(\%)}$ & $95 \%-\mathrm{Cl}$ \\
\hline Cap+Bev & $2(40.0 \%)$ & {$[5.3,85.3]$} & $6(75.0 \%)$ & {$[34.9,96.8]$} & $8(61.5 \%)$ & {$[31.6,86.1]$} \\
\hline Eve+Exe & $1(20.0 \%)$ & {$[0.5,71.6]$} & $1(12.5 \%)$ & {$[0.3,52.7]$} & $2(15.4 \%)$ & {$[1.9,45.4]$} \\
\hline I cannot decide & $2(40.0 \%)$ & {$[5.3,85.3]$} & $1(12.5 \%)$ & {$[0.3,52.7]$} & $3(23.1 \%)$ & {$[5.0,53.8]$} \\
\hline p-value (Chi-square) & & & & & 0.1653 & \\
\hline \multirow[t]{2}{*}{ ITT } & \multicolumn{2}{|c|}{$\operatorname{Arm} A(N=39)$} & \multicolumn{2}{|c|}{$\operatorname{Arm~B}(N=38)$} & \multicolumn{2}{|c|}{ Total $(N=77)$} \\
\hline & n (\%) & $95 \%-\mathrm{Cl}$ & n (\%) & $95 \%-\mathrm{Cl}$ & n (\%) & $95 \%-\mathrm{Cl}$ \\
\hline Cap+Bev & $3(7.7 \%)$ & {$[1.6,20.9]$} & $10(26.3 \%)$ & {$[13.4,43.1]$} & $13(16.9 \%)$ & {$[9.3,27.1]$} \\
\hline Eve+Exe & $5(12.8 \%)$ & {$[4.3,27.4]$} & $2(5.3 \%)$ & {$[0.6,17.7]$} & $7(9.1 \%)$ & {$[3.7,17.8]$} \\
\hline I cannot decide & $3(7.7 \%)$ & {$[1.6,20.9]$} & $4(10.5 \%)$ & {$[2.9,24.8]$} & $7(9.1 \%)$ & {$[3.7,17.8]$} \\
\hline Not evaluable & $2(5.1 \%)$ & {$[0.6,17.3]$} & $2(5.3 \%)$ & {$[0.6,17.7]$} & $4(5.2 \%)$ & {$[1.4,12.8]$} \\
\hline Item / questionnaire not answered & $4(10.3 \%)$ & {$[2.9,24.2]$} & $1(2.6 \%)$ & {$[0.1,13.8]$} & $5(6.5 \%)$ & {$[2.1,14.5]$} \\
\hline No second-line therapy & $22(56.4 \%)$ & {$[39.6,72.2]$} & $19(50.0 \%)$ & {$[33.4,66.6]$} & $41(53.2 \%)$ & {$[41.5,64.7]$} \\
\hline \multirow[t]{2}{*}{ PP } & \multicolumn{2}{|c|}{$\operatorname{Arm~A}(N=13)$} & \multicolumn{2}{|c|}{$\operatorname{Arm~B}(N=18)$} & \multicolumn{2}{|c|}{ Total $(N=31)$} \\
\hline & $n(\%)$ & $95 \%-\mathrm{Cl}$ & $n(\%)$ & $95 \%-\mathrm{Cl}$ & $n(\%)$ & $95 \%-\mathrm{Cl}$ \\
\hline Cap+Bev & $3(23.1 \%)$ & {$[5.0,53.8]$} & $10(55.6 \%)$ & {$[30.8,78.5]$} & $13(41.9 \%)$ & {$[24.5,60.9]$} \\
\hline Eve+Exe & $5(38.5 \%)$ & {$[13.9,68.4]$} & $2(11.1 \%)$ & {$[1.4,34.7]$} & 7 (22.6\%) & {$[9.6,41.1]$} \\
\hline I cannot decide & $3(23.1 \%)$ & {$[5.0,53.8]$} & $4(22.2 \%)$ & {$[6.4,47.6]$} & $7(22.6 \%)$ & {$[9.6,41.1]$} \\
\hline Not evaluable & $2(15.4 \%)$ & {$[1.9,45.4]$} & $2(11.1 \%)$ & {$[1.4,34.7]$} & $4(12.9 \%)$ & {$[3.6,29.8]$} \\
\hline
\end{tabular}

a Patient's treatment preference was evaluated after 12 weeks of second-line treatment, assessed by the Patient Preference Questionnaire. Confidence interval was calculated using the Clopper-Pearson formula. Due to small $n$, the $p$-value of the asymptotic chi-square test may not be valid. The $p$-value of the corresponding exact test was 0.1666 . Not evaluable: Patients selected more than one possible answer. $\mathrm{mITT}=$ modified ITT; ITT = intent-to-treat; $\mathrm{PP}=$ per-protocol; $\mathrm{Cl}=$ confidence interval

\section{Patients' preference}

Overall, $61.5 \%$ of patients reported Cap+Bev as their preferred regimen, though not statistically significant (mITT, $p=0.1653$, Table 3). In Arm A and Arm B, 40\% and $75 \%$ of patients reported $\mathrm{Cap}+\mathrm{Bev}$ as their preferred therapy versus Eve+Exe (Arm A: 20.0\%; Arm B: $12.5 \%)$, respectively. Overall, a similar tendency towards
$\mathrm{Cap}+\mathrm{Bev}$ as the preferred regimen was observed in the PP and ITT populations (Table 3). Notably, 10 of the 13 patients preferring $\mathrm{Cap}+\mathrm{Bev}$ were found in Arm B.

The main reason for preference was improved QoL reported both among patients (ITT population) having preferred Cap+Bev $(n=9 ; 69.2 \%)$ or Eve+Exe $(n=$ $3 ; 42.9 \%)$.

Table 4 Rates of physician's preference ${ }^{a}$ (mITT/ITT/PP population)

\begin{tabular}{|c|c|c|c|c|c|c|}
\hline \multirow[t]{2}{*}{$\overline{\mathrm{mlTT}}$} & \multicolumn{2}{|c|}{$\operatorname{Arm} A(N=5)$} & \multicolumn{2}{|c|}{$\operatorname{Arm} B(N=8)$} & \multicolumn{2}{|c|}{ Total $(N=13)$} \\
\hline & $n(\%)$ & $95 \%-\mathrm{Cl}$ & $n(\%)$ & $95 \%-\mathrm{Cl}$ & $n(\%)$ & $95 \%-\mathrm{Cl}$ \\
\hline Cap+Bev & $3(60.0 \%)$ & {$[14.7,94.7]$} & $3(37.5 \%)$ & {$[8.5,75.5]$} & $6(46.2 \%)$ & {$[19.2,74.9]$} \\
\hline Eve+Exe & $2(40.0 \%)$ & {$[5.3,85.3]$} & $2(25.0 \%)$ & {$[3.2,65.1]$} & $4(30.8 \%)$ & {$[9.1,61.4]$} \\
\hline I cannot decide & 0 & & $3(37.5 \%)$ & {$[8.5,75.5]$} & $3(23.1 \%)$ & {$[5.0,53.8]$} \\
\hline \multirow[t]{2}{*}{ ITT } & \multicolumn{2}{|c|}{$\operatorname{Arm~A}(N=39)$} & \multicolumn{2}{|c|}{$\operatorname{Arm~B~}(N=38)$} & \multicolumn{2}{|c|}{ Total $(N=77)$} \\
\hline & n (\%) & $95 \%-\mathrm{Cl}$ & n (\%) & $95 \%-\mathrm{Cl}$ & n (\%) & $95 \%-\mathrm{Cl}$ \\
\hline Cap+Bev & 10 (25.6\%) & {$[13.0,42.1]$} & $10(26.3 \%)$ & {$[13.4,43.1]$} & $20(26.0 \%)$ & {$[16.6,37.2]$} \\
\hline Eve+Exe & $5(12.8 \%)$ & {$[4.3,27.4]$} & $5(13.2 \%)$ & {$[4.4,28.1]$} & $10(13.0 \%)$ & {$[6.4,22.6]$} \\
\hline I cannot decide & $2(5.1 \%)$ & {$[0.6,17.3]$} & $4(10.5 \%)$ & {$[2.9,24.8]$} & $6(7.8 \%)$ & {$[2.9,16.2]$} \\
\hline \multirow[t]{2}{*}{ PP } & \multicolumn{2}{|c|}{$\operatorname{Arm} A(N=13)$} & \multicolumn{2}{|c|}{$\operatorname{Arm~B}(\mathrm{N}=18)$} & \multicolumn{2}{|c|}{ Total $(N=31)$} \\
\hline & n (\%) & $95 \%-\mathrm{Cl}$ & n (\%) & $95 \%-\mathrm{Cl}$ & n (\%) & $95 \%-\mathrm{Cl}$ \\
\hline Cap+Bev & $8(61.5 \%)$ & {$[31.6,86.1]$} & $10(55.6 \%)$ & {$[30.8,78.5]$} & $18(58.1 \%)$ & {$[39.1,75.5]$} \\
\hline Eve+Exe & $5(38.5 \%)$ & {$[13.9,68.4]$} & $5(27.8 \%)$ & {$[9.7,53.5]$} & $10(32.3 \%)$ & {$[16.7,51.4]$} \\
\hline I cannot decide & 0 & & $3(16.7 \%)$ & {$[3.6,41.4]$} & $3(9.7 \%)$ & {$[2.0,25.8]$} \\
\hline
\end{tabular}

a Physician's preference was evaluated after 12 weeks of second-line treatment, assessed by the Physician Preference Questionnaire. Confidence interval was calculated using the Clopper-Pearson formula. Discrepancies between the sum of patients in the ITT population and the total $n$ reported are due to patients, who did not cross over to the second-line therapy. $\mathrm{mITT}=\mathrm{modified} I T T$; ITT = intent-to-treat; PP = perprotocol; $\mathrm{Cl}=$ confidence interval 
Table 5 Overall treatment satisfaction ${ }^{\mathrm{a}}$ (ITT population)

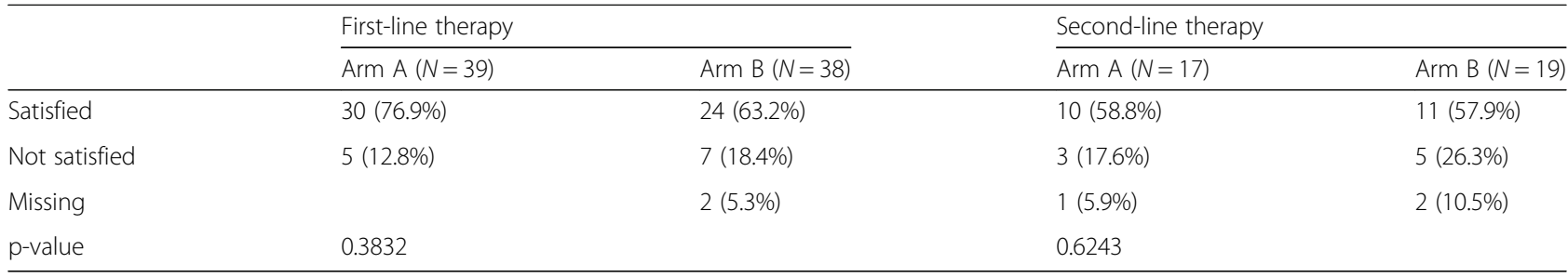

${ }^{a}$ Treatment satisfaction was evaluated in week 12 of each treatment phase, assessed by the Treatment Satisfaction Questionnaire. Second-line: Due to small $\mathrm{n}$, the $p$-value of the asymptotic chi-square test may not be valid. The p-value of the corresponding exact test was 0.6968 . Missing: Item was not answered or not evaluable. Discrepancies between the sum of answers reported and the total $\mathrm{n}$ are due to patients, who did not answer the whole questionnaire

Patient's preference was further evaluated by age $(<60$ years vs. $\geq 60$ years) in the mITT, ITT and PP populations. Overall, a similar pattern towards a preference for Cap+Bev over Eve+Exe was observed in both age groups in all three analytical populations (data not shown).

\section{Physician's preference}

Overall, physicians rated in $46.2 \%$ and $30.8 \%$ of their cases $\mathrm{Cap}+\mathrm{Bev}$ and Eve+Exe as their preferred regimen (mITT, Table 4), respectively. A similar pattern was observed in the PP and ITT populations (Table 4).

\section{Treatment satisfaction}

The majority of the patients in the ITT population in both arms were satisfied with first-line therapy (Arm
A: 76.9\%; Arm B: 63.2\%) and second-line therapy (Arm A: 58.8\%; Arm B: 57.9\%). There was no major difference between arms either in first-line therapy or in second-line therapy (Table 5).

\section{Global health status (EORTC-QLQ-C30)}

Median global health score was 50.0 during the first TP across both arms both at baseline and at week 12 . There was no significant difference in the mean scores of global health status between arms in either TP (ITT, Fig. 3).

\section{Progression-free survival}

Median first-line PFS was longer $(p=0.0008)$ in Arm A (11.1 months) than in Arm B (3.5 months, Fig. 4a).

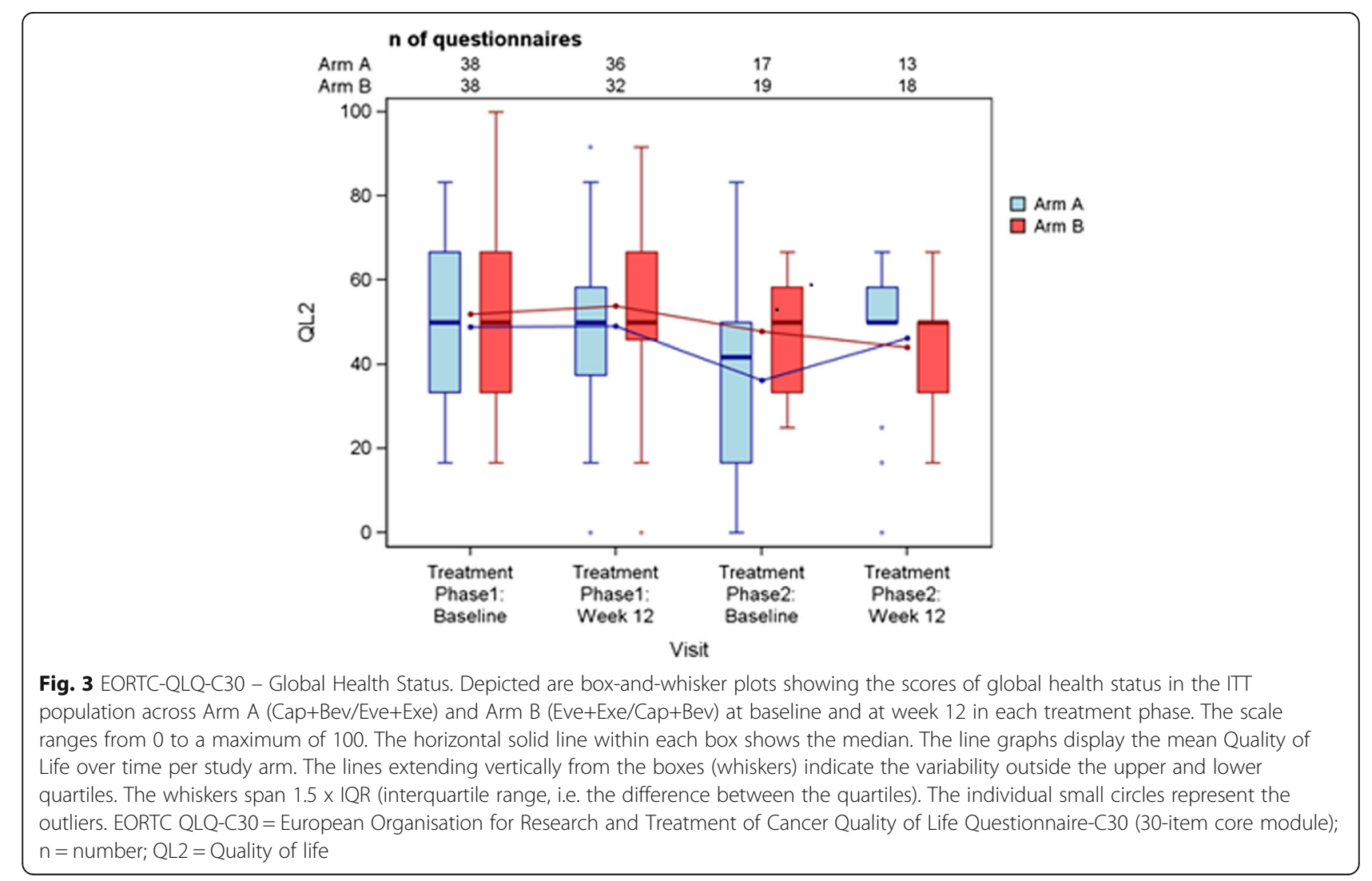


(A)

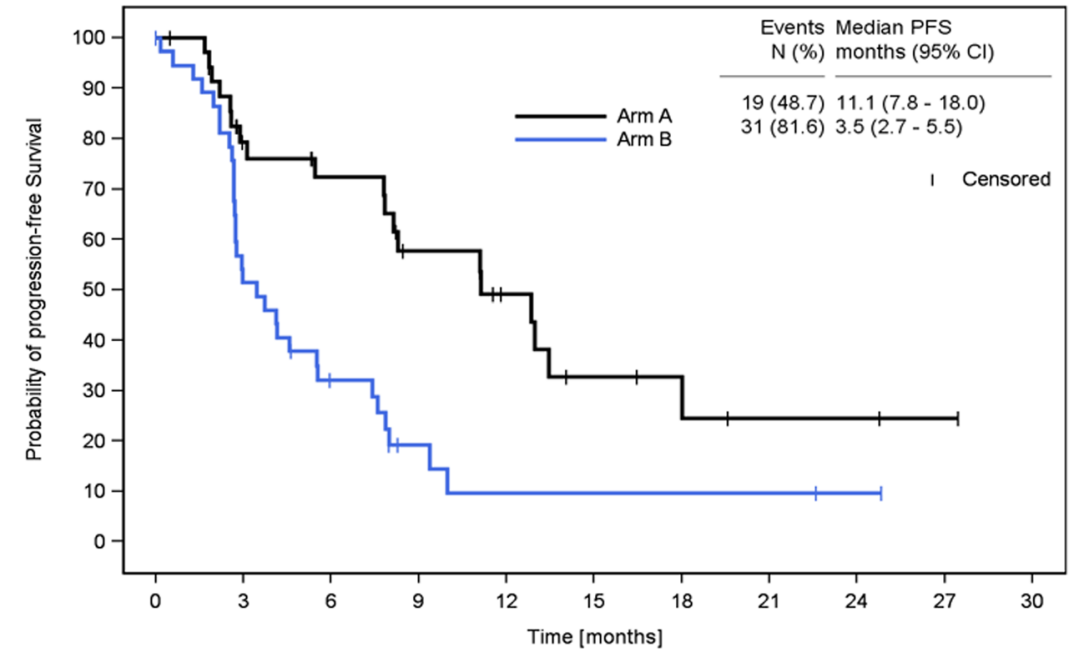

Number at risk

$\begin{array}{cccccccccccc}\text { Arm A } & 39 & 24 & 20 & 14 & 9 & 5 & 3 & 2 & 2 & 1 & 0 \\ \text { Arm B } & 38 & 19 & 10 & 4 & 2 & 2 & 2 & 2 & 1 & 0 & \end{array}$

(B)

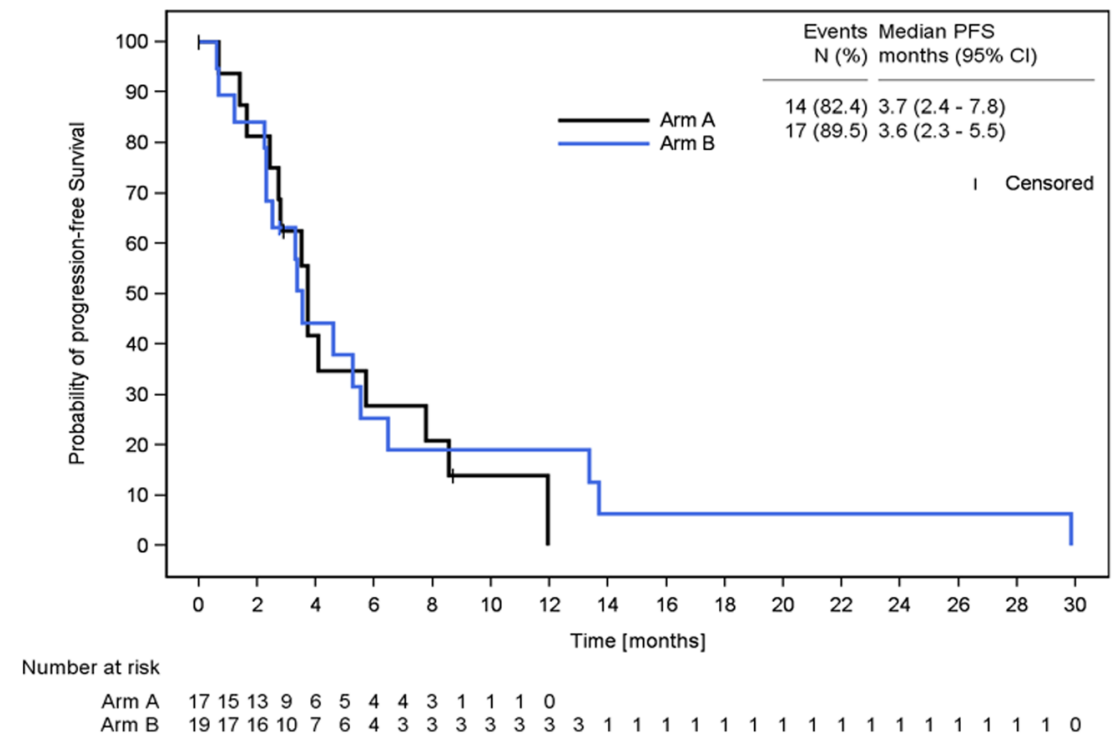

Fig. 4 Kaplan-Meier Estimate of Progression-Free Survival. Displayed are first-line (A) and second-line (B) progression-free survival in Arm A $(\mathrm{Cap}+\mathrm{Bev} / \mathrm{Eve}+\mathrm{Exe})$ and Arm B (Eve+Exe/Cap+Bev) in the ITT population. First-line and second-line progression-free survival were defined as the time from start of first-line / second-line therapy to progression or death due to any cause prior to start of new therapy, respectively. Patients without progression or death were censored at the date of last tumor evaluation in first-line / second-line therapy, respectively. $\mathrm{N}=$ number; PFS = progression-free survival; $\mathrm{Cl}=$ confidence interval

51.3\% of the patients in Arm A were censored for first-line PFS. The estimated 3-month first-line PFS rate was $79.3 \%$ (95\% CI: 61.4-89.6) in Arm A and 51.4\% (95\% CI: 34.4-65.9) in Arm B. There was no major difference $(p=0.8345)$ in median second-line
PFS between Arm A (3.7 months) and Arm B (3.6 months, Fig. 4b). The estimated 3-month second-line PFS rate was similar between Arm A (62.5\%; 95\% CI: 34.9-81.1) and Arm B (63.2\%; 95\% CI: $37.9-$ 80.4). 


\section{Overall survival}

Thirty-one patients (Arm A: $n=13$; Arm B: $n=18$ ) died during the course of the study. There was no major difference $(p=0.2088)$ in median OS between Arm A (28.8 months) and Arm B (24.7 months, Fig. 5).

\section{Safety}

Median duration of $\mathrm{Cap}+\mathrm{Bev}$ therapy (first-line, 6.4 months; second-line, 4.0 months) was longer in both TPs as compared to Eve+Exe therapy (first-line, 3.4 months; second-line, 2.7 months).

Four fatal serious TEAEs (Arm A; $\mathrm{n}=1$; Arm B: $n=3$ ) due to PD were reported during the course of the study; none were attributable to any study drug. $73.0 \%$ and $52.6 \%$ of the patients in Cap+Bev first-line and secondline therapy experienced TEAEs of CTCAE grade 3/4, respectively. $54.1 \%$ and $52.9 \%$ of the patients in Eve+Exe first-line and second-line therapy experienced TEAEs of CTCAE grade $3 / 4$, respectively. Most common TEAEs of CTCAE grade 3/4 were observed in Arm A including hand-foot syndrome (18.9\%) and hypertension (13.5\%) during $\mathrm{Cap}+\mathrm{Bev}$ first-line therapy, and pain (11.8\%) and pneumonia (11.8\%) during Eve+Exe second-line therapy (Table 6).

\section{Discussion}

Current guidelines unequivocally indicate endocrine therapy as the preferred systemic treatment in the vast majority of patients with advanced HR-positive, HER2- negative $\mathrm{BC}[2-4]$. However, this is in contrast to treatment reality; $43 \%$ of these patients are primarily subjected to first-line chemotherapy with $>80 \%$ receiving first-line chemotherapy when aged $\leq 50$ years [19]. The reason for this non-adherence remains unclear at present.

Knowing patients' treatment preference is paramount in patient care. There is a renewed interest in implementation of a shared decision-making process between patients and healthcare, ultimately enhancing treatment quality $[20,21]$. Notably, it has been proven that patients with BC (16\%) value the efficacy less than the sideeffects [22] and are willing to make trade-offs between side-effects and different regimens [23].

Although prematurely terminated, to our knowledge the IMPROVE study is the first randomized study having evaluated patients' preference for either combined chemoand anti-angiogenic therapy (Cap+Bev) or combined endocrine therapy (Eve+Exe) in postmenopausal patients with advanced HR-positive, HER2-negative BC. Furthermore, IMPROVE is the first study to date having compared the efficacy outcome of endocrine-based therapy with an anti-angiogenic-based chemotherapy approach.

In this study, patients tended to favor Cap+Bev over Eve+Exe (mITT), which was in line with physicians' preference. The potential influence from the treating physician should be taken into account. However, the primary endpoint could not be adequately assessed due to low number of observations owing to

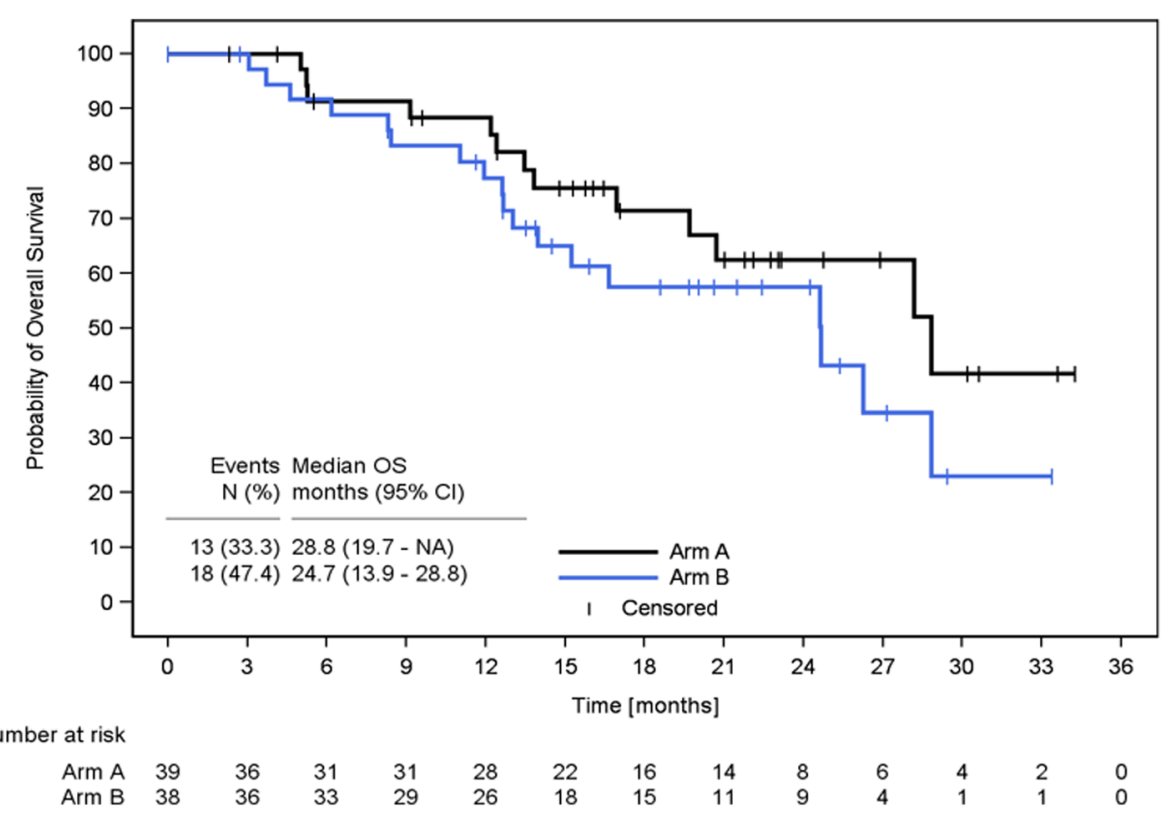

Fig. 5 Kaplan-Meier Estimate of Overall Survival. Displayed is overall survival in Arm A (Cap+Bev/Eve+Exe) and Arm B (Eve+Exe/Cap+Bev) in the ITT population. Overall survival was defined as the time from start of first-line therapy to death due to any cause. Patients without documented date of death at the end of study were censored at the last date known to be alive. $\mathrm{N}=$ number; $\mathrm{OS}=$ overall survival; $\mathrm{Cl}=\mathrm{Confidence} \mathrm{interval;}$ $N A=$ not reached 
Table 6 Treatment-emergent adverse events (> 10\% any grade; SAF population)

\begin{tabular}{|c|c|c|c|c|c|c|c|c|}
\hline & \multicolumn{4}{|l|}{ Arm A } & \multicolumn{4}{|l|}{ Arm B } \\
\hline & \multicolumn{2}{|l|}{$\begin{array}{l}\text { First-line } \\
\text { (Cap+Bev) } \\
N=37\end{array}$} & \multicolumn{2}{|l|}{$\begin{array}{l}\text { Second-line } \\
\text { (Eve+Exe) } \\
N=17\end{array}$} & \multicolumn{2}{|l|}{$\begin{array}{l}\text { First-line } \\
\text { (Eve+Exe) } \\
N=37\end{array}$} & \multicolumn{2}{|l|}{$\begin{array}{l}\text { Second-line } \\
\text { (Cap+Bev) } \\
N=19\end{array}$} \\
\hline & Any grade & $\begin{array}{l}\text { Grade } \\
3 / 4\end{array}$ & Any grade & $\begin{array}{l}\text { Grade } \\
3 / 4\end{array}$ & Any grade & $\begin{array}{l}\text { Grade } \\
3 / 4\end{array}$ & Any grade & $\begin{array}{l}\text { Grade } \\
3 / 4\end{array}$ \\
\hline \multicolumn{9}{|l|}{ Adverse event, $n$ (\%) } \\
\hline Anemia & $1(2.7 \%)$ & & $4(23.5 \%)$ & & $5(13.5 \%)$ & & & \\
\hline Arthralgia & $5(13.5 \%)$ & & & & $4(10.8 \%)$ & & $1(5.3 \%)$ & \\
\hline Bone pain & $3(8.1 \%)$ & & & & $6(16.2 \%)$ & & & \\
\hline Cough & $5(13.5 \%)$ & & $3(17.6 \%)$ & & $6(16.2 \%)$ & & $2(10.5 \%)$ & \\
\hline Decreased appetite & $6(16.2 \%)$ & & $1(5.9 \%)$ & & $5(13.5 \%)$ & & & \\
\hline Diarrhea & $12(32.4 \%)$ & & $2(11.8 \%)$ & & $11(29.7 \%)$ & & $5(26.3 \%)$ & \\
\hline Dyspnea & $6(16.2 \%)$ & & $3(17.6 \%)$ & & $4(10.8 \%)$ & & $4(21.1 \%)$ & \\
\hline Fatigue & $13(35.1 \%)$ & & $3(17.6 \%)$ & & $6(16.2 \%)$ & & $2(10.5 \%)$ & \\
\hline Hand-Foot Syndrome & $21(56.8 \%)$ & 7 (18.9\%) & & & $1(2.7 \%)$ & & $6(31.6 \%)$ & $2(10.5 \%)$ \\
\hline Headache & $6(16.2 \%)$ & & & & $6(16.2 \%)$ & & & \\
\hline Hypertension & $11(29.7 \%)$ & $5(13.5 \%)$ & & & $2(5.4 \%)$ & & $3(15.8 \%)$ & \\
\hline Mucosal inflammation & $4(10.8 \%)$ & & $2(11.8 \%)$ & & 7 (18.9\%) & & & \\
\hline Nausea & 15 (40.5\%) & & $1(5.9 \%)$ & & $9(24.3 \%)$ & & $5(26.3 \%)$ & \\
\hline Edema peripheral & $2(5.4 \%)$ & & & & $6(16.2 \%)$ & & $2(10.5 \%)$ & \\
\hline Pain & $2(5.4 \%)$ & & $2(11.8 \%)$ & $2(11.8 \%)$ & $1(2.7 \%)$ & & & \\
\hline Pleural effusion & $2(5.4 \%)$ & & & & $2(5.4 \%)$ & & $3(15.8 \%)$ & \\
\hline Pneumonia & & & & $2(11.8 \%)$ & $3(8.1 \%)$ & & & \\
\hline PSN & $6(16.2 \%)$ & & & & $1(2.7 \%)$ & & $2(10.5 \%)$ & \\
\hline Stomatitis & $9(24.3 \%)$ & & $1(5.9 \%)$ & & $5(13.5 \%)$ & & $1(5.3 \%)$ & \\
\hline
\end{tabular}

Percentages in second-line therapy refer to the number of patients, who started second-line therapy. Time range: from first administration of study treatment until 30 days after end of treatment in each treatment line. Unrelated TEAEs starting within 30 days of end of first-line therapy and after start of second-line therapy were considered treatment-emergent in both treatment lines in case second-line therapy had started within 30 days of end of first-line therapy. MedDRA v20.0. PSN = Peripheral sensory neuropathy

premature termination of the study and low number of PPQs as a high number of patients did not cross over to second-line therapy. Therefore, the data are of limited interpretability and further conclusions cannot be made. Nevertheless, despite the low number of patients in the mITT population, the data provide important and valuable novel information on patient preference regarding endocrine-based therapy versus anti-angiogenic-based chemotherapy in advanced BC. A similar tendency towards $\mathrm{Cap}+\mathrm{Bev}$ as patients' and physicians' preferred regimen was observed in the PP population. It is intriguing to also look at the ITT population; overall, patients tended to prefer $\mathrm{Cap}+\mathrm{Bev}$ over Eve+Exe. The main reason for deciding for Cap+Bev was improved QoL. However, patientreported QoL was similar in both arms bearing in mind the large variation in QoL scores across arms and TPs. Keeping in mind the small number of evaluable questionnaires in the ITT population, it was nevertheless surprising to see $\mathrm{Cap}+\mathrm{Bev}$ as the preferred regimen, despite the higher percentage of first-line grade 3/4 TEAEs observed in Arm A, possibly attributable to the differences in treatment duration between regimens.

Median first-line PFS was longer in Arm A than in Arm B. The PFS of only 3.5 months in Arm B was unexpected when comparing with the BOLERO-2 trial [10], which reported a superior median PFS of 6.9 months/ 10.6 months (local/central assessment) in the Eve+Exe arm. Possible reasons for the short PFS in our study include the low number of patients in each arm, the slightly shorter DFI and more prior treatments in Arm B versus Arm $A$, the higher percentage of comorbidities observed in Arm B (92.1\%) compared to Arm A (84.6\%) and a higher percentage of patients in Arm B (68.4\%) with prior adjuvant treatment with anthracycline/taxane versus Arm A (56.4\%), possibly reflecting a higher risk profile at initial diagnosis in Arm B. In the BOLERO-6 trial, a median PFS of 8.4 months was reported for Eve+Exe combination therapy versus median 9.6 months 
for Cap monotherapy [24]; although not directly comparable, these results point towards the data in our study. Due to a high number of censored cases in the present study, the OS data are not further interpretable.

The safety profile in this study was consistent with current SmPC of respective drug $[8,9,12,13]$.

\section{Conclusion}

Although prematurely terminated, to our knowledge the IMPROVE study is the first randomized study having evaluated patients' preference for either combined chemo- and anti-angiogenic therapy (Cap+Bev) or combined endocrine therapy (Eve+Exe) in postmenopausal patients with advanced HR-positive, HER2-negative BC. There was a tendency to favor Cap+Bev over Eve+Exe, which was in line with physicians' preference. The efficacy of $\mathrm{Cap}+\mathrm{Bev}$ proved to be superior in terms of firstline PFS. Patient-reported QoL was similar in both arms. No new safety signals were reported.

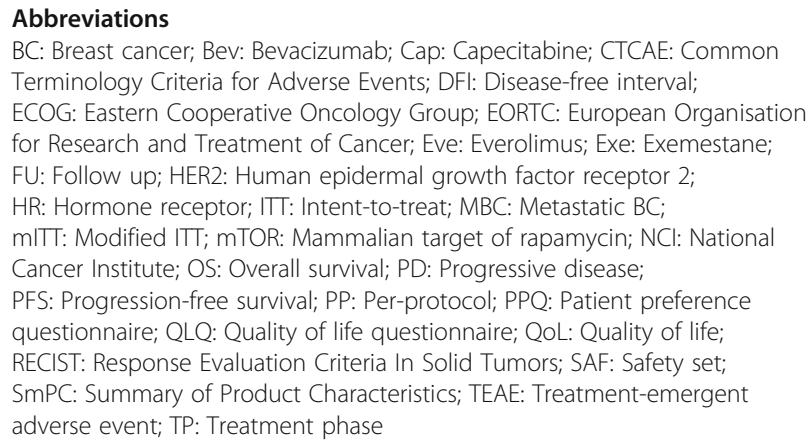

BC: Breast cancer; Bev: Bevacizumab; Cap: Capecitabine; CTCAE: Common Terminology Criteria for Adverse Events; DFI: Disease-free interval; ECOG: Eastern Cooperative Oncology Group; EORTC: European Organisation for Research and Treatment of Cancer; Eve: Everolimus; Exe: Exemestane; FU: Follow up; HER2: Human epidermal growth factor receptor 2; HR: Hormone receptor; ITT: Intent-to-treat; MBC: Metastatic BC; mITT: Modified ITT; mTOR: Mammalian target of rapamycin; NCI: National Cancer Institute; OS: Overall survival; PD: Progressive disease;

PFS: Progression-free survival; PP: Per-protocol; PPQ: Patient preference questionnaire; QLQ: Quality of life questionnaire; QoL: Quality of life; RECIST: Response Evaluation Criteria In Solid Tumors; SAF: Safety set; SmPC: Summary of Product Characteristics; TEAE: Treatment-emergent adverse event; TP: Treatment phase

\section{Acknowledgements}

The authors thank all patients, physicians and study teams participating in this study. We would also like to thank Dr. med. Norbert Marschner (iOMEDICO), Dr. med. Jens Hasskarl (iOMEDICO), Dr. med. Kirsten Hauswald (iOMEDICO), and Dr. med. Tanja Trarbach (iOMEDICO) for support during study design, Melanie Frank (iOMEDICO) for writing the statistical analysis plan and for performing a large part of the statistical analysis, Dr. med. Leonora Houet (iOMEDICO) for support during data analysis and critical review of the manuscript, Dr. Andrea Kiemen (iOMEDICO) for support during the writing of the study protocol, and Dr. Christian Johansson (iOMEDICO) for the writing of the clinical study report and preparation of the manuscript. This project was supported financially by Novartis Pharma GmbH, Germany.

\section{Consent to publish}

Not applicable.

\section{Authors' contributions}

TD, JF, MI, ER and KP were involved in conception and design, analysis and interpretation of the data, and reviewed the paper for intellectual content and gave their approval of the final version of the manuscript to be published. MC performed statistical analysis, analyzed and interpreted the data, and reviewed the paper for intellectual content and approved the final version of the manuscript to be published. US, AH, CM, CMK, UVK, DS, PK and $\mathrm{VH}$ collected data and reviewed the paper for intellectual content and gave their approval of the final version of the manuscript to be published.

\section{Funding}

This iOMEDICO-sponsored project received financial support from Novartis Pharma GmbH, Germany. Novartis had no role in the study design, data collection and analysis, interpretation of results, decision to publish, or preparation of the manuscript.

\section{Availability of data and materials}

Clinical data were documented in electronic Case Report Forms (eCRFs; iostudy office edc, iOMEDICO) and are the property of iOMEDICO. The data are not publicly available due to them containing information that could compromise patient and/or research participant privacy / consent.

\section{Ethics approval and consent to participate}

The study protocol was approved by all relevant bodies (BfArM, Bonn, Germany). The study received positive opinions from the consulting Ethics Committee of the State Chamber of Physicians at the Federal States of Berlin, Bremen, Dessau-Roßlau, Dresden, Düsseldorf, Frankfurt a.M., Hamburg, Hannover, Mainz, München, Münster, Saarbrücken and Stuttgart as well as from the Ethics Committees at the Medical Faculty of the Universities of Bochum, Essen, Greifswald, Heidelberg, Mannheim and Würzburg, Germany. The study was conducted in accordance with Good Clinical Practice and all procedures performed in studies involving human participants were in accordance with the ethical standards of the institutional and/or national research committee and with the 1964 Helsinki declaration and its later amendments or comparable ethical standards. The study adheres to CONSORT guidelines. Written informed consent was obtained from all individual participants included in the study.

\section{Competing interests}

Thomas Decker: CONSULTANT OR ADVISORY ROLE: Novartis.

Ulrike Söling: No conflict of interest.

Antje Hahn: No conflict of interest.

Christoph Maintz: No conflict of interest.

Christian Martin Kurbacher: HONORARIA: Amgen, Eli Lilly, Mundipharma, Novartis, Pfizer, Roche, Tesaro; CONSULTANT OR ADVISORY ROLE: Amgen, Eli Lilly, Mundipharma, Novartis, Pfizer, Riemser, Roche, Tesaro; RESERACH FUNDING: Astra Zeneca, MSD Sharp \& Dohme (Merck), Novartis, Pfizer, Seattle Genetics; TRAVEL, ACCOMODATIONS: Amgen, Hexal, PharmaMar, Pfizer, Tesaro.

Ursula Vehling-Kaiser: No conflict of interest.

Dagmar Sent: No conflict of interest.

Peter Klare: No conflict of interest.

Volker Hagen: HONORARIA: Amgen, BMS, Celgene, FomF, Gilead, Janssen Cilag, IOMEDICO, Pfizer, Roche; SHAREHOLDINGS: Bristol-Myers Squibb, Johnson \& Johnson

Marco Chiabudini: No conflict of interest.

Julia Falkenstein: No conflict of interest.

Martin Indorf: No conflict of interest.

Eva Runkel: No conflict of interest.

Karin Potthoff: No conflict of interest.

\section{Author details}

'Gemeinschaftspraxis für Hämatologie und Onkologie GbR, Elisabethenstrasse 19, 88212 Ravensburg, Germany. ${ }^{2}$ Onkologische Gemeinschaftspraxis, Goethestrasse 47, 34119 Kassel, Germany. ${ }^{3}$ Klinikum Mittelbaden Baden-Baden Bühl, Balger Strasse 50, 76532 Baden-Baden Weststadt, Germany. ${ }^{4}$ Hämatologisch-Onkologische Praxis, Mauerfeldchen 72, 52146 Würselen, Germany. ${ }^{5}$ Gynäkologisches Zentrum Bonn, Friedenplatz 16, 53111 Bonn, Germany. ${ }^{6}$ Hämatologisch-onkologische Tagesklinik, Achdorfer Weg 5, 84036 Landshut, Germany. ${ }^{7}$ Klinikum Leverkusen gGmbH, Am Gesundheitspark 11, 51375 Leverkusen, Germany. ${ }^{8}$ MediOnko-Institut GbR, Möllendorffstr. 52, 10367 Berlin, Germany. ${ }^{9}$ St.-Johannes-Hospital, Johannesstr. 9-17, 44137 Dortmund, Germany. ${ }^{10}$ iOMEDICO AG, Ellen-Gottlieb-Straße 19, 79106 Freiburg im Breisgau, Germany.

Received: 18 October 2019 Accepted: 12 March 2020

Published online: 06 April 2020

\section{References}

1. O'Shaughnessy J. Extending survival with chemotherapy in metastatic breast cancer. Oncologist. 2005;10(Suppl 3):20-9 https://doi.org/10.1634/ theoncologist.10-90003-20.

2. Burstein HJ, Lacchetti C, Anderson H, Buchholz TA, Davidson NE, Gelmon KA, Giordano SH, Hudis CA, Solky AJ, Stearns V, Winer EP, Griggs JJ. 
Adjuvant endocrine therapy for women with hormone receptor-positive breast cancer: ASCO clinical practice guideline focused update. J Clin Oncol Off J Am Soc Clin Oncol. 2018:JCO1801160 https://doi.org/10.1200/JCO.18. 01160.

3. Cardoso F, Senkus E, Costa A, Papadopoulos E, Aapro M, André F, Harbeck N, Lopez BA, Barrios CH, Bergh J, Biganzoli L, Boers-Doets CB, Cardoso MJ, Carey LA, Cortés J, Curigliano G, Diéras V, El Saghir NS, Eniu A, Fallowfield L, Francis PA, Gelmon K, Johnston SRD, Kaufman B, Koppikar S, Krop IE, Mayer M, Nakigudde G, Offersen BV, Ohno S, Pagani O, Paluch-Shimon S, PenaultLlorca F, Prat A, Rugo HS, Sledge GW, Spence D, Thomssen C, Vorobiof DA, Xu B, Norton L, Winer EP. 4th ESO-ESMO international consensus guidelines for advanced breast cancer (ABC 4)t. Ann Oncol Off J Eur Soc Med Oncol. 2018;29:1634-57 https://doi.org/10.1093/annonc/mdy192.

4. O'Sullivan CC, Loprinzi CL, Haddad TC. Updates in the evaluation and management of breast cancer. Mayo Clin Proc. 2018;93:794-807 https://doi. org/10.1016/.mayocp.2018.03.025

5. Wilcken N, Hornbuckle J, Ghersi D. Chemotherapy alone versus endocrine therapy alone for metastatic breast cancer. Cochrane Database Syst Rev. 2003:CD002747 https://doi.org/10.1002/14651858.CD002747.

6. Miller KD, Chap LI, Holmes FA. Randomized phase III trial of Capecitabine compared with Bevacizumab plus Capecitabine in patients with previously treated metastatic breast Cancer. J Clin Oncol. 2005;23:792-9 https://doi. org/10.1200/JCO.2005.05.098.

7. Robert NJ, Diéras V, Glaspy J, Brufsky AM, Bondarenko I, Lipatov ON, Perez EA, Yardley DA, Chan SYT, Zhou X, Phan S-C, O'Shaughnessy J. RIBBON-1: randomized, double-blind, placebo-controlled, phase III trial of chemotherapy with or without bevacizumab for first-line treatment of human epidermal growth factor receptor 2-negative, locally recurrent or metastatic breast cancer. J Clin Oncol Off J Am Soc Clin Oncol. 2011;29: 1252-60 https://doi.org/10.1200/JCO.2010.28.0982

8. Avastin $25 \mathrm{mg} / \mathrm{ml}$ concentrate for solution for infusion - Summary of Product Characteristics (SmPC) - (eMC). n.d. https://www.medicines.org.uk/ emc/product/3885/smpc. Accessed 6 Apr 2018.

9. Xeloda $150 \mathrm{mg}$ and $500 \mathrm{mg}$ film-coated tablets - Summary of Product Characteristics (SmPC) - (eMC). n.d. https://www.medicines.org.uk/emc/ product/1319/smpc. Accessed 6 Apr 2018.

10. Baselga J, Campone M, Piccart M, Burris HA III, Rugo HS, Sahmoud T, Noguchi S, Gnant M, Pritchard Kl, Lebrun F. Everolimus in postmenopausal hormone-receptor-positive advanced breast cancer. N Engl J Med. 2012; 366:520-9.

11. Yardley DA, Noguchi S, Pritchard KI, Burris HA, Baselga J, Gnant M, Hortobagyi GN, Campone M, Pistilli B, Piccart M, Melichar B, Petrakova K, Arena FP, Erdkamp F, Harb WA, Feng W, Cahana A, Taran T, Lebwohl D, Rugo HS. Everolimus plus Exemestane in postmenopausal patients with HR+ breast Cancer: BOLERO-2 final progression-free survival analysis. Adv Ther. 2013;30:870-84 https://doi.org/10.1007/s12325-013-0060-1.

12. Afinitor 10mg tablets - Summary of Product Characteristics (SmPC) - (eMC). n.d. https://www.medicines.org.uk/emc/product/6658/smpc. Accessed 6 Apr 2018.

13. Aromasin - Summary of Product Characteristics (SmPC) - (eMC). n.d. https:// www.medicines.org.uk/emc/product/5520. Accessed 6 Apr 2018.

14. Eisenhauer EA, Therasse P, Bogaerts J, Schwartz LH, Sargent D, Ford R, Dancey J, Arbuck S, Gwyther S, Mooney M, Rubinstein L, Shankar L, Dodd L, Kaplan R, Lacombe D, Verweij J. New response evaluation criteria in solid tumours: revised RECIST guideline (version 1.1). Eur J Cancer. 2009;45:228-47 https://doi.org/10.1016/j.ejca.2008.10.026.

15. Aaronson NK, Ahmedzai S, Bergman B, Bullinger M, Cull A, Duez NJ, Filiberti A, Flechtner H, Fleishman SB, de Haes JC. The European Organization for Research and Treatment of Cancer QLQ-C30: a quality-of-life instrument for use in international clinical trials in oncology. J Natl Cancer Inst. 1993;85: $365-76$

16. CTCAE 4.03 2010-06-14_QuickReference 5x7.pdf. n.d. https://www.eortc.be/ services/doc/ctc/CTCAE_4.03_2010-06-14_QuickReference_5x7.pdf. Accessed 6 Apr 2018.

17. Escudier B, Porta C, Bono P, Powles T, Eisen T, Sternberg CN, Gschwend JE, Giorgi UD, Parikh O, Hawkins R, Sevin E, Négrier S, Khan S, Diaz J, Redhu S, Mehmud F, Cella D. Randomized, controlled, double-blind, cross-over trial assessing treatment preference for pazopanib versus sunitinib in patients with metastatic renal cell carcinoma: PISCES study. J Clin Oncol. 2014:JCO. 2013.50.8267 https://doi.org/10.1200/JCO.2013.50.8267.
18. Kaplan EL, Meier P. Nonparametric estimation from incomplete observations. J Am Stat Assoc. 1958;53:457-81 https://doi.org/10.2307/ 2281868.

19. Hartkopf AD, Huober J, Volz B, Nabieva N, Taran F-A, Schwitulla J, Overkamp F, Kolberg H-C, Hadji P, Tesch H, Häberle L, Ettl J, Lux MP, Lüftner D, Wallwiener M, Müller V, Beckmann MW, Belleville E, Wimberger P, Hielscher C, Geberth M, Fersis N, Abenhardt W, Kurbacher C, Wuerstlein R, Thomssen C, Untch M, Fasching PA, Janni W, Fehm TN, Wallwiener D, Brucker SY, Schneeweiss A. Treatment landscape of advanced breast cancer patients with hormone receptor positive HER2 negative tumors - Data from the German PRAEGNANT breast cancer registry. Breast. 2017:37:42-51 https:// doi.org/10.1016/j.breast.2017.10.002.

20. Berger AM, Buzalko RJ, Kupzyk KA, Gardner BJ, Djalilova DM, Otte JL. Preferences and actual chemotherapy decision-making in the greater plains collaborative breast cancer study. Acta Oncol Stockh Swed. 2017;56:1690-7 https://doi.org/10.1080/0284186X.2017.1374555.

21. Gustafson A. Reducing patient uncertainty: implementation of a shared decision-making process enhances treatment quality and provider communication. Clin J Oncol Nurs. 2017;21:113-5 https://doi.org/10.1188/17. CJON.113-115.

22. Wouters H, Maatman GA, Van Dijk L, Bouvy ML, Vree R, Van Geffen ECG, Nortier JW, Stiggelbout AM. Trade-off preferences regarding adjuvant endocrine therapy among women with estrogen receptor-positive breast cancer. Ann Oncol Off J Eur Soc Med Oncol. 2013;24:2324-9 https://doi.org/ 10.1093/annonc/mdt195.

23. Beusterien K, Grinspan J, Kuchuk I, Mazzarello S, Dent S, Gertler S, Bouganim $\mathrm{N}$, Vandermeer $\mathrm{L}$, Clemons M. Use of conjoint analysis to assess breast cancer patient preferences for chemotherapy side effects. Oncologist. 2014; 19:127-34 https://doi.org/10.1634/theoncologist.2013-0359.

24. Jerusalem G, de Boer RH, Hurvitz S, Yardley DA, Kovalenko E, Ejlertsen B, Blau S, Özgüroglu M, Landherr L, Ewertz M, Taran T, Fan J, Noel-Baron F, Louveau $A-L$, Burris $H$. Everolimus plus exemestane vs everolimus or capecitabine monotherapy for estrogen receptor-positive, HER2-negative advanced breast cancer: the BOLERO- 6 randomized clinical trial. JAMA Oncol. 2018:e182262 https://doi.org/10.1001/jamaoncol.2018.2262.

\section{Publisher's Note}

Springer Nature remains neutral with regard to jurisdictional claims in published maps and institutional affiliations.

Ready to submit your research? Choose BMC and benefit from:

- fast, convenient online submission

- thorough peer review by experienced researchers in your field

- rapid publication on acceptance

- support for research data, including large and complex data types

- gold Open Access which fosters wider collaboration and increased citations

- maximum visibility for your research: over $100 \mathrm{M}$ website views per year

At $\mathrm{BMC}$, research is always in progress.

Learn more biomedcentral.com/submissions 